\title{
Molecular Analysis of Single-Nucleotide Polymorphisms of TRAF5 Gene in Patients with Behçet's Disease from the Azeri Population of Northwest Iran
}

\author{
Reza Hosseinzadeh ${ }^{1}$, Leila Saremi², Sepideh Babaniamansour ${ }^{3}$, Mohammad Ebrahim Ghaffari ${ }^{4}$, Mohammad Khalaj-Kondori ${ }^{*}$ (D) \\ ${ }^{1}$ MS, Department of Genetic, East Azarbayjan Sciences and Research Branch, Islamic Azad University, Tabriz, Iran. \\ ${ }^{2} \mathrm{PhD}$, Department of Biology, Science and Research Branch, Islamic Azad University, Tehran, Iran. \\ ${ }^{3} \mathrm{MD}$, School of Medicine, Islamic Azad University Tehran, Faculty of Medicine, Tehran, Iran. \\ ${ }^{4} \mathrm{PhD}$ in Biostatistics, Dental Sciences, Research Center, Faculty of Dentistry, Guilan University of Medical Sciences, Rasht, IRAN. \\ ${ }^{5} \mathrm{PhD}$, Department of Animal Biology Faculty of Natural Sciences, University of Tabriz, Tabriz, Iran.
}

*Corresponding author: Mohammad Khalaj-Kondori, Associate Professor of Molecular Genetics, Department of Animal Biology Faculty of Natural Sciences, University of Tabriz, Tabriz, Iran. ORCID: 0000-0003-3990-5467.

Received date: June 17, 2021; Accepted date: August 11, 2021; Published date: Augusł 20, 2021

Citation: R Hosseinzadeh, L Saremi, S Babaniamansour, Mohammad E Ghaffari, Mohammad K Kondori. (2021) Molecular Analysis of SingleNucleotide Polymorphisms of TRAF5 Gene in Patients with Behçet's Disease from the Azeri Population of Northwest Iran. International Journal of Clinical Case Reports and Reviews. 8(2); DOI:10.31579/2690-4861/148

Copyright: (C) 2021 Mohammad Khalaj-Kondori, This is an open-access article distributed under the terms of the Creative Commons Attribution License, which permits unrestricted use, distribution, and reproduction in any medium, provided the original author and source are credited.

\begin{abstract}
Background: Behçet's disease (BD) is a chronic inflammatory disease with unknown causes. The geographical distribution is mostly consistent with the historic Silk Road. The role of tumor necrosis factor receptor-associated factor 5 (TRAF5) gene in the inflammation signaling pathway leads more attention to the potency of different polymorphisms of the TRAF5 gene, in the development of BD.
\end{abstract}

Methods: This was a case-control study conducted among the Azeri Turk ethnic group (50 BD patients and 50 persons with no history of autoimmune disease), Tabriz, Iran. Four different TRAF5 gene polymorphisms were assessed via the Polymerase Chain Reaction-Restriction Fragment Length Polymorphism technique. Data were analyzed by SPSS Version 20.

Results: Genotypic distributions of four studied Single nucleotide polymorphisms (SNPs) had no significant difference between case and control groups ( $r$ 6540679 $(\mathrm{p}=0.50), \operatorname{rs} 12569232(\mathrm{p}=0.86), \operatorname{rs} 10863888(\mathrm{p}=0.14)$, and rs7514863 $(\mathrm{p}=0.24)$. There were also found no significant differences in SNP allelic frequencies between cases and controls (all $P>$ $0.05)$.

Conclusions: Although the role of the TRAF5 gene polymorphisms in inflammatory diseases has been proved, our study did not show a significant association between the TRAF5 gene polymorphisms with BD.

Keywords: behçet syndrome; genetic polymorphism; human traf5 protein; polymerase chain reaction

\section{Background}

Behçet's disease (BD) is a multifactorial inflammatory and systemic uveitis autoimmune disease, which is associated with recurrent skin lesions, oral aphthae, and genital ulcers with unknown causes [1-6]. The highest incidence of BD belongs to Turkey (80-370 patients in 100,000 persons), whereas it has a low rate in North America ( 0.2 patients in 100,000 people) [7]. The onset age of the disease is usually between 25 and 30 years old [8]. The disease is equally distributed between genders, but the previous studies reported higher severity in males than females for unknown reasons. Although numerous studies have been done, the main causes of the BD are still unclear [9].

Recently, the role of various active oxygen derivatives (free radicals) including superoxide, hydroxyl peroxide, hydroxyl radicals, and nitric oxide as well as the activity of antioxidant enzymes (dismutase oxide and 
glutathione peroxidase) in the pathogenesis of BD were examined. These elements have been considered as transcription activators of proinflammatory cytokines $[10,11]$. Additionally, a wide range of mutations and polymorphisms in association with BD patients have been reported, such as human leukocyte antigen (HLA-B) serotype 5, chemokine receptor 5 , heat shock protein 60 , anti-tumor necrosis factor (TNF) $\alpha$, Interleukin-6 (IL-6), and Interferon-gamma (IFN- $\gamma$ ), Cluster of differentiation 40 (CD40), signal transducer and activator of transcription 3 (STAT3), STAT4, and Janus kinase 2 (JAK2) [9, 12], Intercellular adhesion molecule-1, small ubiquitin-like modifier 4, IL-23R-IL12RB2, IL10, Monocyte chemoattractant protein-1, and Fc receptor-like 3 [13].

Moreover, dominant immune responses in the patients are considered important factors in its pathogenesis. The physicians choose Corticosteroids, Colchicine, Azathioprine, Cyclosporine, Thalidomide, Cyclophosphamide, Interferon- $\alpha$, or TNF $\alpha$ inhibitors as the BD treatment based on the severity of the organ involvement and clinical symptoms [14].

Tumor necrosis factor receptor-associated factors (TRAFs) are an intracellular family of adaptor proteins that share a common structural domain

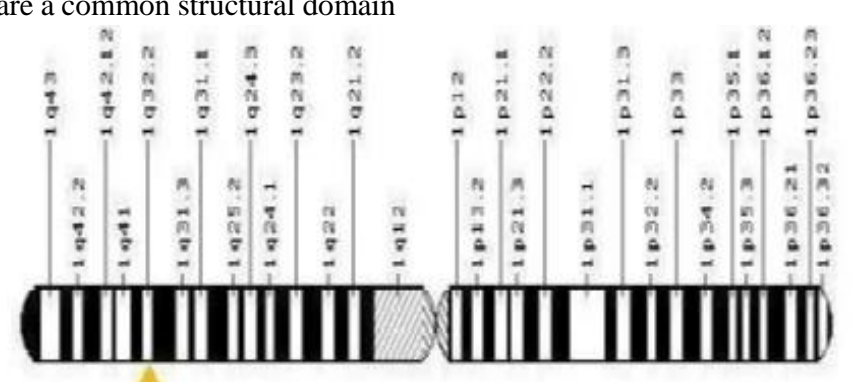

Figure 1: Chromosomal location of TRAF5.

Single nucleotide polymorphism (SNP) in TARF is related to autoimmune diseases such as lupus erythematosus, rheumatoid arthritis (RA) [22-25]. Xiang et al. demonstrated that TRAF5 polymorphisms are related to susceptibility to autoimmune diseases such as RA. An SNP (rs7514863) upstream of TRAF5 that affects a transcriptional factor binding site is associated with RA [26]. A major dominant mutation in TRAF3 was reported in a young child with a herpes simplex virus (HSV1) encephalitis history [27]. A TRAF6 heterozygous mutation has been recently reported in a patient with Hypohidrotic Ectodermal Dysplasia [28]. In 2014, the association between rs 10863888 and BD was observed in a Chinese population [20].

We selected four SNPs (rs1256932, rs6540679, rs10863888, and rs7514863) for the investigation of TRAF5 polymorphisms based on reports in psoriasis and RA [29], linkage disequilibrium patterns in Han Chinese, and Japanese data in the Hap Map database.

\section{Methods}

\section{Study design}

This was a case-control study conducted at the Molecular-Medical Genetic department of Islamic Azad University East Azarbaijan Science and Research Branch, Tabriz, Iran. The executive protocol of the study was conducted under the Declaration of Helsinki (seventh revision 2013). All participants had written consent before the study. at the C-terminus and directly attach to TNF receptors (TNF-R) $[15,16]$. There are seven known types of TRAF family (TRAF1 to 7) in mammals [17]. All TRAFs, except TRAF1, consist of an N-terminal ring finger domain followed by the various number of zinc fingers $[16,18]$. The ring finger consists of one histidine residue and seven cysteine residues forming a single folded domain binding two zinc ions. In ubiquitin ligases, ring finger motifs are vital for ubiquitin molecule transfer to substrates or ring finger motifs themselves. TRAFs are related to various diseases such as immunodeficiency, cancer pathogenesis, autoimmune, and neurodegenerative [19].

The TRAF5 identified as a CD40 binding protein and a lymphotoxin-b receptor-interacting protein (LTBR), locates on the humans' chromosome 1q32.2. (Figure 1) It significantly expresses in the thymus gland, lungs, spleen, kidneys as well as peripheral blood cells and plays an important role in cell signaling [20]. TRAF5 using the yeast two-hybrid system, and LBR, by PCR using degenerate primers corresponding to conserved amino acids in the TRAF domain of TRAF1-3 [21].

\section{Participants}

In this study, the case group included 50 BD patients from the Azeri Turk ethnic group, diagnosed by a rheumatologist (26 males and 24 females in each group). The control group included 50 persons with neither history of autoimmune disease nor a family history of autoimmune disease.

\section{Genomic deoxyribonucleic acid (DNA) extraction using the Salting out method}

A venous blood sample $(5 \mathrm{cc})$ was obtained from all participants and collected in Ethylenediaminetetraacetic acid (EDTA, Merck Company, Germany)-containing falcon (SARSTEDT Company, Germany). The samples were shaken slowly to mix and prevent the formation of blood clots. DNA was extracted from blood samples based on the Nasiri et. al, methods [30]. The quantity and quality of extracted DNA were determined using spectrophotometry and agarose gel (Kosar Company, Iran) electrophoresis, respectively.

\section{Polymerase Chain Reaction (PCR)}

PCR (ABI Company, USA) was performed to amplify specific DNA sequences using specific primers (manufactured by Biorad Company, Germany). Amplification conditions for PCR reactions were as follows: one cycle at $95{ }^{\circ} \mathrm{C}$ for $5 \mathrm{~min}, 30$ cycles at $94{ }^{\circ} \mathrm{C}$ for $25 \mathrm{~s}, 63{ }^{\circ} \mathrm{C}$ for $20 \mathrm{~s}$ and $72{ }^{\circ} \mathrm{C}$ for $20 \mathrm{~s}$, followed by a final extension at $72{ }^{\circ} \mathrm{C}$ for $5 \mathrm{~min}$. PCR 
products were electrophoresed on agarose gels (2\%), stained with the ethidium bromide (manufactured by CinnaGen, Iran), and documented.

\section{Digestion of PCR-products with restriction enzymes (PCR -} RFLP)

PCR-Restriction Fragment Length Polymorphism (RFLP) is commonly used to examine the various alleles of a gene in a population. The sequence diversity of the gene corresponding alleles creates different digestion locations for the restriction enzyme, and segments with different lengths are obtained. Induced mutations in the detection site of restriction enzymes (TRUII-SacI-TSP509I-APOI-hinfI, manufactured by Fermentas company, Germany) and resulted polymorphism can be detected by its RFLP pattern. After amplification of the mentioned DNA segments, PCR products were digested using restriction enzymes. Each reaction tubes

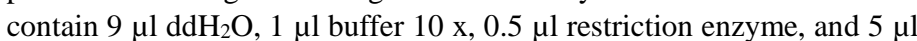
PCR product, then incubated overnight at $37^{\circ} \mathrm{C}$. The position information of each of the polymorphisms, restriction enzymes, and DNA fragment size is listed in table 1 . Finally, the incubated reactions were electrophoresed on agarose $3 \%$ and documented.

\begin{tabular}{|c|c|c|c|c|}
\hline Gene & SNPID & Primer & $\begin{array}{c}\text { Restriction } \\
\text { Enzyme }\end{array}$ & Fragment Size (bp) \\
\hline \multirow{8}{*}{ TRAF5 } & \multirow[t]{2}{*}{ rs6540679 } & 5-TGTGTCTAAAGGGCCATGTG-3 & \multirow[t]{2}{*}{ XmiI (AccI) } & \multirow[t]{2}{*}{$233(133-100)$} \\
\hline & & 5-CTTAGAGACCCTGCTCACCC-3 & & \\
\hline & \multirow[t]{2}{*}{ rs12569232 } & 5-AGATGAAACAACTGAGGCACA-3 & \multirow[t]{2}{*}{ MvaI (BstNI) } & \multirow[t]{2}{*}{$305(220-85)$} \\
\hline & & 5-ACTGCCTTTGGTTTGACAGTC-3 & & \\
\hline & \multirow[t]{2}{*}{ rs10863888 } & 5-ATCTCATCTGATTAACTTC/GTC-3 & \multirow[t]{2}{*}{ Mae III } & \multirow[t]{2}{*}{$311(288-24)$} \\
\hline & & 5-CTCTTCAGAGACTGAGTCA-3 & & \\
\hline & \multirow[t]{2}{*}{ rs 7514863} & 5-CCATCTCATCTGATTAACTTCTC-3 & \multirow[t]{2}{*}{ Tsp45I } & \multirow[t]{2}{*}{$254(231-23)$} \\
\hline & & 5-TTTGATGACTGTCTCGCTGG-3 & & \\
\hline
\end{tabular}

Table 1: Primers, enzymes, and the size of the digested fragments using digestion enzymes

\section{Statistical analysis}

A Chi-square test with continuity correction was used to examine the Hardy-Weinberg equilibrium. After it was found that Hardy-Weinberg equilibrium is established in all polymorphisms, Chi-square and Fisher's exact tests were used to compare the frequency of alleles and genotypes between case and control groups. To perform calculations, $\mathrm{R}$ version 3.4.3 and SPSS version 20 (SPSS Inc., Chicago, IL, USA) were used to analyze the data. $\mathrm{P}<0.05$ was considered statistically significant.

\section{Results}

The present study was conducted among 100 participants. The mean age of participants in the case and control groups were $34.02 \pm 7.39$ (range 11 to 65 ) and $34.42 \pm 8.27$ (range 21 to 76 ) years, respectively. Patients in the case group had no family history of BD. The frequency of the positive Pathergy test in the case and control groups were 14(28\%) and zero, respectively. The clinical characteristic of the case group is shown in table 2.

\begin{tabular}{|c|c|c|}
\hline \multicolumn{2}{|c|}{ Variables } & Case group (N=50) \\
\hline \multicolumn{2}{|c|}{ Oral Aphthosis } & $47(94)$ \\
\hline \multicolumn{2}{|c|}{ Genital Aphthosis } & $22(44)$ \\
\hline \multirow{3}{*}{ Skin manifestations } & Erythema nodosum & $5(10)$ \\
\cline { 2 - 3 } & Pseudolliculitis & $11(22)$ \\
\hline \multirow{3}{*}{ Ocular } & Anterior uveitis & $27(54)$ \\
\cline { 2 - 3 } & posterior uveitis & $31(62)$ \\
\cline { 2 - 3 } & Retinal vasculitis & $5(10)$ \\
\cline { 2 - 3 } & Cataract & $14(28)$ \\
\hline \multicolumn{2}{|c|}{ Vascular involvement } & $6(12)$ \\
\hline \multicolumn{2}{|c|}{ Neurological involvement } & $1(2)$ \\
\hline \multicolumn{2}{|c|}{ Arthritis } & $6(12)$ \\
\hline
\end{tabular}

Data were described as frequency (percent).

Table 2: Clinical characteristics of case group.

In this study, four polymorphisms (rs12569232, rs6540679, rs7514863, and rs10863888) of the TRAF5 gene were evaluated. To investigate the polymorphism of rs6540679 (SNP: rs6540679 Chr.1: 211491152) a segment about 233 bp was amplified using PCR followed by digestion using the Xmil (ACC I) enzyme, which PCR products that contain allele
(G) was not digested but a product with allele (A) digested and fragments with 100 and $133 \mathrm{bp}$ were produced. The people who were heterozygous for the given site showed three bands with lengths of 133, 100, and 233 bp. (Figure 2) 


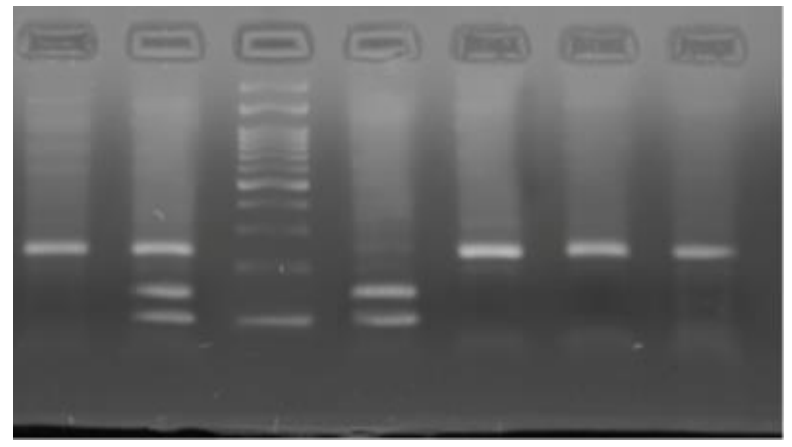

Figure 2. Polymorphism of rs6540679.

Lane C: Ladder 100 bp, Lane A, E, F and G: GG genotype (rs6540679) (233 bp), lane D: AA genotype (rs6540679) (100, 133 bp), Lane B: AG genotype (rs6540679) (100, 133, 233 bp).

To assess the polymorphism of rs12569232 (SNP: rs12569232 Chr.1: 211553064) a segment, about 305 bp was amplified using PCR followed by digestion using the Mva I (BstNI) enzyme, which PCR products contain allele $(\mathrm{C})$ was not digested but a product with allele $(\mathrm{G})$ digested and fragments 220 and 85 bp were produced. The people who were heterozygous for the given site showed three segments with lengths of 220, 85, and 305 bp. (Figure 3)

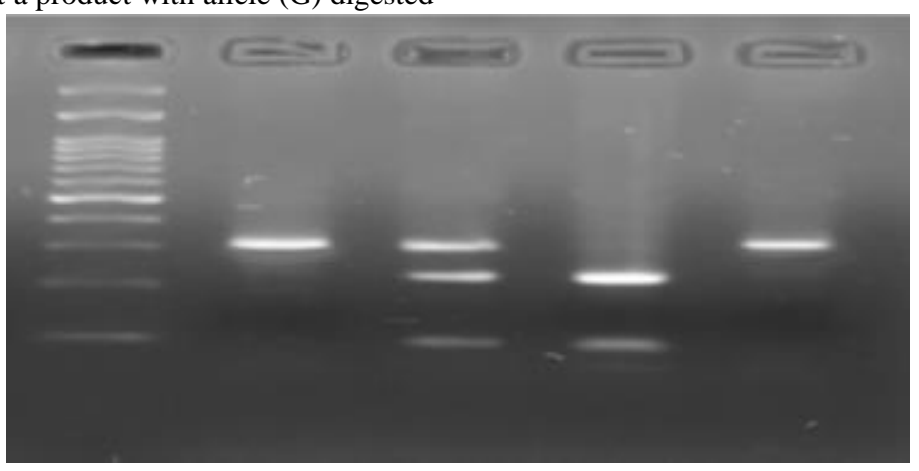

Figure 3. Polymorphism of rs 12569232.

Lane A: Ladder 100 bp, Lane B and E: CC genotype (rs12569232) (305 bp), Lane D: GG genotype (rs 12569232) (85, 220 bp), Lane C: CG genotype (rs12569232) $(85,220,305 \mathrm{bp})$.

To study the polymorphism of rs10863888 (SNP: rs10863888 Chr.1: 211502769) a fragment about 311 bp was amplified using PCR followed by digestion using the Mae III enzyme, which PCR products that contain allele (A) digested, but allele (G) was not digested and fragments with 288 and 24 bp produced. The heterozygous people for the given site showed three bands with lengths of 288, 24 and, $311 \mathrm{bp}$. (Figure 4)

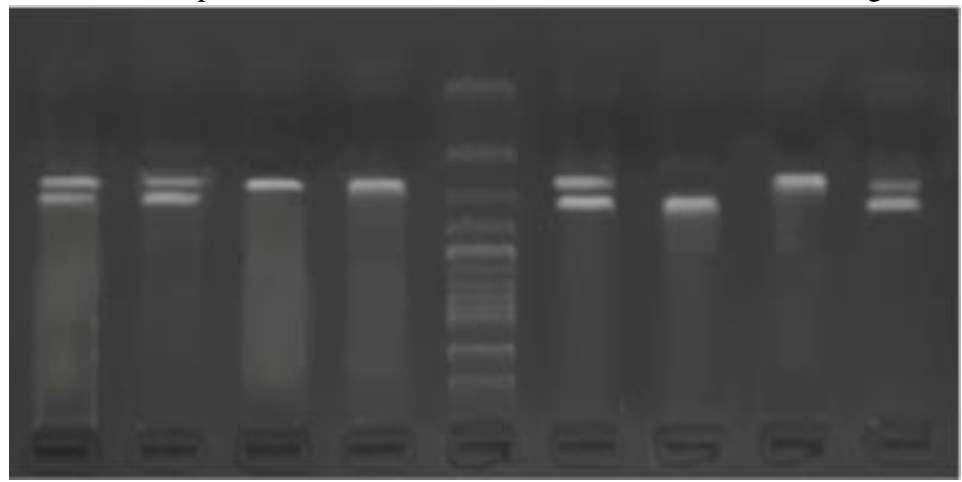

Figure 4. Polymorphism of rs10863888. Lane E: Ladder 100 bp.

To assess the polymorphism of rs7514863 a fragment of about $254 \mathrm{bp}$ was amplified and followed by digestion using the Tsp 451 enzyme, which PCR products contain allele (A) digested but a product with allele (G) was not digested and fragments 231 and 23 bp were produced. The heterozygous individuals for the given site showed three segments with lengths of 254, 231, and $23 \mathrm{bp}$. (Figure 5) 


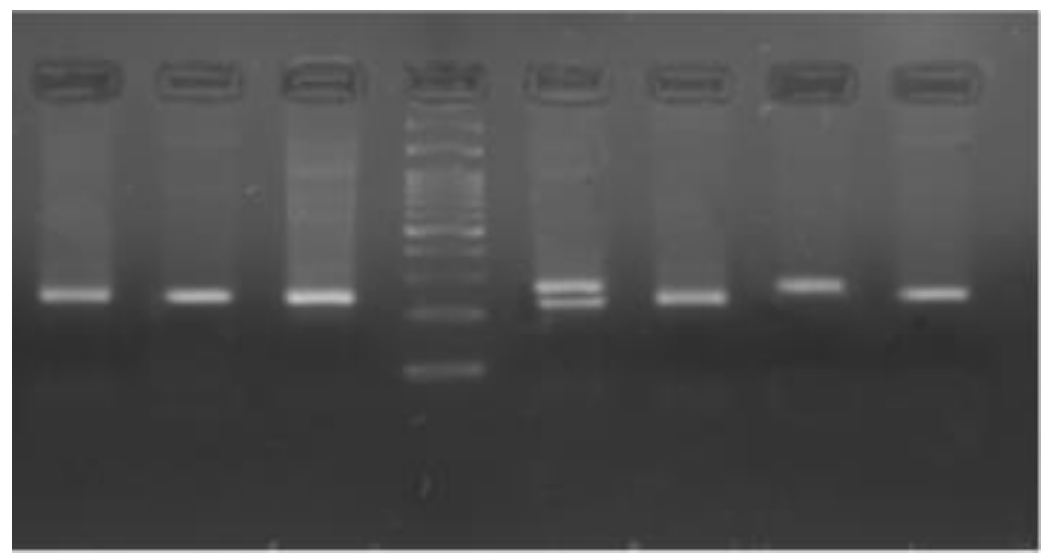

Figure 5. Polymorphism of rs7514863. Lane D: Ladder $100 \mathrm{bp}$.

Tables 3 and 4 show the frequency of allele and genotype in four different polymorphisms of the TRAF5 gene between case and control groups. The results showed no significant difference for rs6540679 polymorphism $(\mathrm{P}=0.92)(\mathrm{OR}=0.895,0.41-1.94), \mathrm{rs} 12569232(\mathrm{P}=0.75, \mathrm{OR}=1.17,0.61-$
2.24), rs10863888 $(\mathrm{P}=0.088 ; \mathrm{OR}=1.76,0.97-3.21)$ and $\mathrm{rs} 7514863$ $(\mathrm{P}=0.65, \mathrm{OR}=0.674,0.23-1.967)$ between case and control groups. (Table $5)$.

\begin{tabular}{|c|c|c|c|c|c|c|c|c|c|}
\hline \multirow[t]{2}{*}{ SNP } & \multicolumn{2}{|c|}{ rs6540679 } & \multirow{2}{*}{$\begin{array}{l}\mathrm{P}- \\
\text { value }\end{array}$} & \multirow[t]{2}{*}{ OR $(95 \%$ CI $)$} & \multirow[t]{2}{*}{ SNP } & \multicolumn{2}{|c|}{ rs12569232 } & \multirow[t]{2}{*}{ P-value } & \multirow[t]{2}{*}{ OR $(95 \% \mathrm{CI})$} \\
\hline & $\mathrm{A}$ & $\mathrm{G}$ & & & & $\mathrm{G}$ & $\mathrm{C}$ & & \\
\hline Case & 14 & 86 & \multirow[t]{2}{*}{0.780} & \multirow{2}{*}{$\begin{array}{l}0.895(0.412- \\
1.94)\end{array}$} & Case & 25 & 75 & \multirow[t]{2}{*}{0.627} & \multirow[t]{2}{*}{$1.17(0.61-2.24)$} \\
\hline Control & 16 & 88 & & & Control & 23 & 81 & & \\
\hline \multirow[t]{2}{*}{ SNP } & \multicolumn{2}{|c|}{ rs10863888 } & \multirow{2}{*}{$\begin{array}{l}\mathrm{P}- \\
\text { value }\end{array}$} & \multirow[t]{2}{*}{ OR $(95 \% \mathrm{CI})$} & \multirow[t]{2}{*}{ SNP } & \multicolumn{2}{|c|}{ rs7514863 } & \multirow[t]{2}{*}{ P-value } & \multirow[t]{2}{*}{ OR $(95 \% \mathrm{CI})$} \\
\hline & $\mathrm{A}$ & $\mathrm{G}$ & & & & $\mathrm{A}$ & $\mathrm{G}$ & & \\
\hline Case & 37 & 63 & \multirow[t]{2}{*}{0.064} & \multirow{2}{*}{$\begin{array}{l}1.76(0.966- \\
3.21)\end{array}$} & Case & 6 & 94 & \multirow[t]{2}{*}{0.468} & \multirow{2}{*}{$\begin{array}{l}0.674(0.23- \\
1.967)\end{array}$} \\
\hline Control & 26 & 78 & & & Control & 9 & 95 & & \\
\hline
\end{tabular}

p-value refers to the association of the frequency of alleles between case and control groups, based on Pearson Chi-Square. SNP: Single Nucleotide Polymorphism; OR: Odds Ratio; CI: Confidence Interval.

Table 3: The frequency of each allele between case and control groups

\begin{tabular}{|c|c|c|c|c|c|c|c|c|c|}
\hline \multirow[t]{2}{*}{ SNP } & \multicolumn{3}{|c|}{ rs6540679 } & P-value & \multirow[t]{2}{*}{ SNP } & \multicolumn{3}{|c|}{ rs 12569232} & P-value \\
\hline & $\overline{\mathrm{AA}}$ & $\mathrm{AG}$ & GG & \multirow{3}{*}{$0.509^{\mathrm{b}}$} & & $\mathrm{CC}$ & $\mathrm{CG}$ & GG & \multirow{3}{*}{$0.860^{\mathrm{b}}$} \\
\hline Case & 1 & 12 & 37 & & Case & 4 & 17 & 29 & \\
\hline Control & 0 & 16 & 36 & & Control & 3 & 17 & 32 & \\
\hline \multirow[t]{2}{*}{ SNP } & \multicolumn{3}{|c|}{ rs 10863888} & $\mathrm{P}$-value & SNP & \multicolumn{3}{|c|}{ rs7514863 } & $\mathrm{P}$-value \\
\hline & $\mathrm{AA}$ & $\mathrm{AG}$ & GG & \multirow{3}{*}{$0.141^{\mathrm{a}}$} & & $\mathrm{AA}$ & AG & GG & \multirow{3}{*}{$0.236^{\mathrm{b}}$} \\
\hline Case & 7 & 23 & 20 & & Case & 1 & 4 & 45 & \\
\hline Control & 5 & 16 & 31 & & Control & 0 & 9 & 43 & \\
\hline
\end{tabular}

p-value refers to the association of the frequency of alleles between case and control groups. ${ }^{\text {a }}$ refers to the analysis based on Pearson Chi-Square. ${ }^{b}$ refers to the analysis based on Fisher's Exact Test. SNP: Single Nucleotide Polymorphism.

Table 4: The frequency of each genotype between case and control groups.

\begin{tabular}{|c|c|c|c|c|c|c|c|c|c|c|c|c|c|}
\hline \multirow[t]{3}{*}{ SNPs } & \multicolumn{6}{|c|}{ Genotype } & \multirow{3}{*}{$\begin{array}{l}\mathrm{P}- \\
\text { value }\end{array}$} & \multicolumn{4}{|c|}{ Allele } & \multirow{3}{*}{$\begin{array}{l}\mathrm{P}- \\
\text { value }\end{array}$} & \multirow[t]{3}{*}{ OR $(95 \% \mathrm{CI})$} \\
\hline & \multicolumn{2}{|l|}{$\mathrm{mm}$} & \multicolumn{2}{|c|}{$\mathrm{mM}$} & \multicolumn{2}{|c|}{ MM } & & \multicolumn{2}{|l|}{$\mathrm{M}$} & \multicolumn{2}{|l|}{$\mathrm{M}$} & & \\
\hline & $\mathrm{BD}$ & $\mathrm{CON}$ & $\mathrm{BD}$ & $\mathrm{CON}$ & $\mathrm{BD}$ & $\mathrm{CON}$ & & $\mathrm{BD}$ & $\mathrm{CON}$ & $\mathrm{BD}$ & $\mathrm{CON}$ & & \\
\hline rs6540679 & 1 & 0 & 12 & 16 & 37 & 36 & 0.50 & 14 & 16 & 86 & 88 & 0.780 & $0.895(0.41-1.95)$ \\
\hline rs12569232 & 4 & 3 & 17 & 17 & 29 & 32 & 0.86 & 25 & 23 & 75 & 81 & 0.627 & $1.17(0.61-2.24)$ \\
\hline rs10863888 & 7 & 5 & 23 & 16 & 20 & 31 & 0.14 & 37 & 26 & 63 & 78 & 0.064 & $1.76(0.97-3.21)$ \\
\hline rs7514863 & 1 & 0 & 4 & 9 & 45 & 43 & 0.24 & 6 & 9 & 94 & 95 & 0.468 & $0.674(0.23-1.967)$ \\
\hline
\end{tabular}

BD: Behçet Disease; CON: Control group; M: normal allele; m: mutant allele; MM: normal-normal genotype; mm: mutant-mutant genotype; Mm: normal-mutant genotype. p-value refers to the association of the frequency of alleles between case and control groups, based on Pearson Chi-Square. SNP: Single Nucleotide Polymorphism. 


\section{Discussion}

In this study, the relationship between common polymorphisms of the TRAF5 gene and BD in the Azari-Iranian population was studied. Although the cause of BD has not been fully characterized, however, it seems that genetic and environmental factors contribute to the disease. For example, HLA-B51 is commonly found in BD patients around the Silk Road.

The results of this study showed that there was no relationship between polymorphisms of rs6540679, rs12569232, rs10863888, and rs7514863 with the susceptibility to the BD.

The relationship between autoimmune diseases like BD and the TRAF5 gene polymorphisms was assessed in the previous studies but they showed contradictory results. Potter et al. conducted a study among 351 BD patients and 368 persons (as a control group) in England. They examined 44 markers of the TRAF gene such as rs7514863 and showed a strong relationship between the TRAF5 gene polymorphism (rs7514863) and RA. Potter suggested that this marker can be a candidate polymorphism for RA [26].

Xiang et al. studied markers of rs 12569232, rs6540679, and rs 10863888 in 450 acute anterior uveitis autoimmune patients, 458 pediatric uveitis patients, and 1601 persons as a control group in China. There was a significant relationship between polymorphism of rs12569232 and disease, but no significant relationship was observed for rs6540679 and rs10863888 [31].

In the study on 789 BD and 940 patients suffering Vogt-Koyanagi-Harada Syndrome in China, rs10563888 marker was significantly associated with $\mathrm{BD}$, while there was no significant association for rs6540679 and rs12569232 [20]. Studies stated that TNF- $\alpha$ and MEFV polymorphisms had a significant association with BD in Iranian Azeri Turkish [32, 33]. High expression of JAK1 and TLR2 in patients with BD confirmed the important role of this gene in its development [34].

A study among BD patients in China showed that AG and GG alleles of rs 10863888 polymorphism had a significant difference. We thought that if the number of patients and the control group considered on a larger scale the significance of this polymorphism would be very high. Although the $\mathrm{P}$-value obtained for rs 10863888 polymorphism in this study is 0.088 , confirms our hypothesis that this polymorphism may be meaningful in the case of a larger patient and control community.

Differences in the results of various studies on the association between the TRAF5 gene polymorphism and BD can be justified for several reasons. First, this difference can be due to the genetic variation of studied populations in various studies, which indicates the presence of different polymorphism levels in different populations. On the other hand, this inconsistency could be due to the low number of surveyed people and used techniques. Thus, it is recommended to carry out more extensive studies with more samples and more precise techniques, including sequencing of the fragments using DNA sequencing techniques.

\section{Conclusions}

Although the role of the TRAF5 gene polymorphisms in inflammatory diseases has been proved in many investigations, Our study did not show a significant relationship between the TRAF5 gene polymorphisms and BD.

\section{List of abbreviations}

BD: Behçet's Disease; TRAF: Tumor Necrosis Factor ReceptorAssociated Factor; SPSS: Statistical Package for the Social Sciences; SNP: Single Nucleotide Polymorphism; HLA: Human Leukocyte Antigen; TNF: Tumor Necrosis Factor; IL: Interleukin; IFN: Interferon; CD: Cluster of Differentiation; STAT: Signal Transducer and Activator of Transcription; JAK: Janus Kinase; LTBR: Lymphotoxin-b ReceptorInteracting Protein; RA: Rheumatoid Arthritis; HSV: Herpes Simplex Virus; DNA: Deoxyribonucleic Acid; EDTA: Ethylenediaminetetraacetic Acid; PCR: Polymerase Chain Reaction; RFLP: Restriction Fragment Length Polymorphism.

\section{Declaration:}

Ethic approval: The implementation of the project was approved by the ethics committee of Islamic Azad University East Azarbaijan Science.

Consent to participate: Informed consent was obtained from all the participants prior to the study.

\section{Consent for publication: Not applicable.}

Availability of data and material: Data sharing is available upon the author's request.

Funding: This research did not receive any specific grant from funding agencies in the public, commercial, or not-for-profit sector.

Competing Interests: On behalf of all authors, the corresponding author states that there is no conflict of interest.

\section{Authors' contributions}

Leila Saremi, Sepideh Babaniamansour, Reza Hosseinzadeh and Mohammad Khalaj-Kondori were in charge of samples collection, experimental design and PCR. Leila Saremi, Mohammad KhalajKondori, and Mohammad Ebrahim Ghaffari contributed equally performed and designed experiments, analyzed data, and generated figures. Reza Hosseinzadeh, and Sepideh Babaniamansour were in charge of idea and concept of the paper. Mohammad Ebrahim Ghaffari, Sepideh Babaniamansour and Mohammad Khalaj-Kondori assisted in supervision and .generated figures and edited the manuscript All authors read and approved the final manuscript.

\section{Acknowledgements}

We thank Dr. Aziz Khorrami for his excellent technical assistance and contributions in this study.

\section{References}

1. Karatay S, Yildirim K, Karakuzu A, Kiziltunc A, Engin RI, Eren YB, et al. (2011) Vitamin D status in patients with Behcet's Disease. Clinics. 66(5):721-723.

2. Karray EF, Dhifallah IB, Abdelghani KB, Ghorbel IB, Khanfir M, Houman H, et al. (2012) Associations of vitamin D receptor gene polymorphisms FokI and BsmI with susceptibility to rheumatoid arthritis and Behçet's disease in Tunisians. Joint Bone Spine. 79(2):144-148.

3. Kolahi S, Khabbazi A, Khodadadi H, Estiar M, Hajialiloo M, Emrahi L, et al. (2015) Vitamin D receptor gene polymorphisms in Iranian Azary patients with Behçet's disease. Scandinavian journal of rheumatology. 44(2):163-167.

4. Ershadinia N, Mortazavinia N, Babaniamansour S, NajafiNesheli M, Babaniamansour P, Aliniagerdroudbari E. (2020) The prevalence of autoimmune diseases in patients with 
multiple sclerosis: A cross-sectional study in Qom, Iran, in 2018. Current Journal of Neurology. 19(3):98-102.

5. Jadideslam G, Kahroba H, Ansarin K, Sakhinia E, Abhar A, Alipour S, et al. (2020) Interleukin-17 mRNA expression and serum levels in Behçet's disease. Cytokine.

6. Nouri-Vaskeh M, Malek Mahdavi A, Khabbazi A, Jadideslam G. (2019) Lack of association between serum IL-9 levels and Behçet's disease. Immunology Letters. 211:23-27.

7. Hitchon CA, Sun Y, Robinson DB, Peschken CA, Bernstein CN, Siminovitch KA, et al. (2012) Vitamin D receptor polymorphism rs2228570 (Fok1) is associated with rheumatoid arthritis in North American natives. The Journal of rheumatology. 39(9):1792-1797.

8. Hymowitz SG, Wertz IE. (2010) A20: from ubiquitin editing to tumour suppression. Nature Reviews Cancer. 10(5):332-341.

9. Vereecke L, Beyaert R, van Loo G. (2009) The ubiquitinediting enzyme A20 (TNFAIP3) is a central regulator of immunopathology. Trends in immunology. 30(8):383-391.

10. Mizuki N, Ota M, Katsuyama Y, Yabuki K, Ando H, Shiina T, et al. (2001) HLA-B* 51 allele analysis by the PCR-SBT method and a strong association of HLA-B* 5101 with Japanese patients with Behçet's disease. HLA. 58(3):181-184.

11. Hamzaoui K, Dhtfallah I, Karray E, Sassi F, Hamzaoui A. (2010) Vitamin D modulates peripheral immunity in patients with Behcet's disease. Clinical \& Experimental Rheumatology. 28(4):S50.

12. Shang YB, Zhai N, Li JP, Han SX, Ren QS, Song FJ, et al. (2009) Study on association between polymorphism of HLADRB1 alleles and Behçet's disease. Journal of the European Academy of Dermatology and Venereology. 23(12):14191422.

13. Hou S, Yang Z, Du L, Jiang Z, Shu Q, Chen Y, et al. (2012) Genome-wide association study identifies susceptible locus in STAT4 for Behcet's disease in Han Chinese. Arthritis Rheum. 64(12):4104-4113.

14. Arekhi S, Ghodsi A, Omranzadeh A, Rahimi HR. (2021). Does adaptive $\mathrm{T}$ cell immunity have any role in the pathophysiology and histopathology of Buerger's disease? Journal of Basic Research in Medical Sciences. 8(1):1-9.

15. Inoue $\mathrm{J}-\mathrm{i}$, Ishida $\mathrm{T}$, Tsukamoto $\mathrm{N}$, Kobayashi $\mathrm{N}$, Naito $\mathrm{A}$, Azuma S, et al. (2000) Tumor necrosis factor receptorassociated factor (TRAF) family: adapter proteins that mediate cytokine signaling. Experimental cell research. 254(1):14-24.

16. Wajant H, Henkler F, Scheurich P. (2001) The TNF-receptorassociated factor family: scaffold molecules for cytokine receptors, kinases and their regulators. Cellular signalling. 13(6):389-400.

17. Salahshour F, Mehrabinejad M-M, Dehnavi AZ, Alibakhshi A, Dashti H, Ataee M-A, et al. (2020). Pancreatic neuroendocrine tumors (pNETs): the predictive value of MDCT characteristics in the differentiation of histopathological grades. Abdominal Radiology. 45(10):3155-3162.

18. Ha H, Han D, Choi Y. (2009) TRAF-mediated TNFR-family signaling. Current protocols in immunology. 11(9); 1-9.

19. Ostuni R, Zanoni I, Granucci F. (2010) Deciphering the complexity of Toll-like receptor signaling. Cellular and molecular life sciences. 67(24):4109-4134.

20. Xiang Q, Chen L, Hou S, Fang J, Zhou Y, Bai L, et al. (2014) TRAF5 and TRAF3IP2 gene polymorphisms are associated with Behcet's disease and Vogt-Koyanagi-Harada syndrome: a case-control study. PloS one. 9(1).

21. Bradley JR, Pober JS. (2001) Tumor necrosis factor receptorassociated factors (TRAFs). Oncogene. 20(44):6482-6491.
22. Zervou MI, Sidiropoulos $\mathrm{P}$, Petraki E, Vazgiourakis V, Krasoudaki E, Raptopoulou A, et al. (2008) Association of a TRAF1 and a STAT4 gene polymorphism with increased risk for rheumatoid arthritis in a genetically homogeneous population. Human immunology. 69(9):567-571.

23. Kurreeman FS, Alizadeh BZ, Goulielmos GN, Rueda B, Houwing-Duistermaat J, Sánchez E, et al. (2009) The TRAF1C5 region on chromosome 9q33 is associated with multiple autoimmune diseases. Annals of the rheumatic diseases.

24. Lee YH, Song GG. (2012) Associations between TNFSF4 and TRAF1-C5 gene polymorphisms and systemic lupus erythematosus: a meta-analysis. Human immunology. 73(10):1050-1054.

25. Shahidi M, Rashtchizadeh N, Ghorbani haghjo A, Rezaei Moghadam A, Taghizadeh M, Marzban H. (2013) Comparison of Serum Matrix Gla-protein (MGP) with Osteoprotegerin (OPG) and Correlation with Disease Severity (DAS) in Women Patients with Rheumatoid Arthritis. New Cellularand Molecular Biotechnology Journal. 3(11):37-45.

26. Potter C, Eyre S, Cope A, Worthington J, Barton A. (2007) Investigation of association between the TRAF family genes and RA susceptibility. Annals of the rheumatic diseases. 66(10):1322-1326.

27. De Diego RP, Sancho-Shimizu V, Lorenzo L, Puel A, Plancoulaine S, Picard C, et al. (2010) Human TRAF3 adaptor molecule deficiency leads to impaired Toll-like receptor 3 response and susceptibility to herpes simplex encephalitis. Immunity. 33(3):400-411.

28. Wisniewski SA, Trzeciak WH. (2012) A new mutation resulting in the truncation of the TRAF6-interacting domain of XEDAR: a possible novel cause of hypohidrotic ectodermal dysplasia. Journal of medical genetics. 49(8):499-501.

29. Muppidi JR, Tschopp J, Siegel RM. (2004) Life and death decisions: secondary complexes and lipid rafts in TNF receptor family signal transduction. Immunity. 21(4):461-465.

30. Nasiri H, Forouzandeh M, Rasaee M, Rahbarizadeh F. (2005) Modified salting-out method: high-yield, high-quality genomic DNA extraction from whole blood using laundry detergent. Journal of clinical laboratory analysis. 19(6):229-232.

31. Xiang Q, Chen L, Fang J, Hou S, Wei L, Bai L, et al. (2013) TNF receptor-associated factor 5 gene confers genetic predisposition to acute anterior uveitis and pediatric uveitis. Arthritis research \& therapy. 15(5).

32. Bonyadi M, Jahanafrooz Z, Esmaeili M, Kolahi S, Khabazi A, Ebrahimi AA, et al. (2009) TNF- $\alpha$ gene polymorphisms in Iranian Azeri Turkish patients with Behcet's Disease. Rheumatology international. 30(2):285-289.

33. Esmaeili M, Bonyadi M, Khabbazi A, Ebrahimi A, Sharif S, Hajialilo M, et al. (2011) Common MEFV mutations in Iranian Azeri Turkish patients with Behçet's disease. Scandinavian journal of rheumatology. 40(5):383-386.

34. Mueswr TC, Schall C, Debouver N, Ogbuoji E, Drago VN, editors. (2018). Crystal Growth in Microgravity for Neutron Diffraction Studies.

35. Ghodsi A, Mirimoghaddam MM, Sarabi M, Rahimi HR. (2020). Neutrophil-to-lymphocyte ratio as a novel and valuable marker for assessing disease severity in Ulcerative colitis, Multiple sclerosis, and Kawasaki disease: A review. 